\title{
Reading Between the Lines: Event-related Brain Potentials during Natural Sentence Processing
}

\author{
Marta Kutas and Steven A. Hillyard \\ University of California, San Diego
}

\begin{abstract}
Event-related potentials (ERPs) were recorded from subjects as they silently read 160 different seven-word sentences, presented one word at a time. Each sentence was in itself a natural, meaningful phrase. Substantial intersubject variability was observed in the ERP waveshapes following the words. More than half of the subjects generated P3 components to word stimuli, but those who did showed similar responses to repeated control presentations of a single word. In addition, it was found that all but the first word in the sentence elicited an ERP with a significant left-greater-than-right asymmetry in the late positivity over temporo-parietal regions. The ERPs to the last words were associated with more late positivity than those to the preceding words. One quarter of the sentences, at random, ended with a word printed in a typeface that was different from that of the preceding words. This infrequent change in typeface elicited a complex ERP having three consistent late positive components.
\end{abstract}

\section{INTRODUCTION}

Reading is fundamental for the acquisition of knowledge in literate societies and a stalwart member of the three R's. Yet, we know astonishingly little about the neurophysiological mechanisms which enable us to read a sentence and comprehend its meaning. The only currently feasible approach to understanding normal human neurophysiology involves the recording of event-related potentials (ERPs) from the scalp. While this technique has the advantage of being nonintrusive, it provides a rather remote index of the complex neuronal activity patterns which underly human language processes.

There have been some attempts to use evoked potentials to differentiate normal from learning-disabled readers (Shipley \& Jones, 1969; Conners,

This research was supported by grants from NSF-BNS 77-14923 and NIMH, USPHS MH25594. We thank J. C. Hansen for providing various computer programs and J. C. Phillips and S. Van Voorhis for invaluable technical assistance. Send reprint request to Dr. Marta Kutas, Department of Neurosciences, M-008, University of California. San Diego. La Jolla, CA 92093. 
1970; Ross, Childers, \& Perry, 1973; Sobotka \& May, 1977; Weber \& Omenn, 1977). However, only a few of these studies have recorded ERPs to words (Preston, Guthrie, \& Childs, 1974; Preston, Guthrie, Kirsch, Gertman, \& Childs, 1977; Symann-Lovett, Gascon, Matsumiya, \& Lombroso, 1977; Preston, 1979); the approach has generally been to detail the parameters of the evoked potentials to light flashes, rather than to assess subjects' graphological, syntactic, or semantic capacities or limitations. Similarly, very few investigations have used the ERP technology to study the processing and comprehension of natural written language. Those that have used rather restricted paradigms such as the repeated presentations of a few simple sentences which limited the generality of their results (Friedman, Simson, Ritter, \& Rapin, 1975b; Goto, Adachi, Utsunomiya, \& Chen, 1979).

The present report is the first in a series of experiments on the ERPs obtained during natural sentence processing. ERPs were recorded from three midline and two lateral sites as subjects silently read 160 different seven-word sentences, one word at a time. While the subjects' task was to read for content, $25 \%$ of the sentences, at random, ended in a word with a different typeface than that of the preceding words. In this manner, we were able to collect data bearing on a number of issues, including the nature of ERP components accompanying the processing of words, the extent to which the ERP might index the differential engagement of the cerebral hemispheres during reading, and finally, the question of whether late positive (P3 or P300) waves are triggered by unexpected shifts in stimulus attributes that are wholly irrelevant to the task.

\section{Hemispheric Asymmetries}

The functional differences between the left and right cerebral hemispheres have been well documented over the past 15 years. Whatever the exact nature of these differences, it is generally acknowledged that linguistic analyses are carried out primarily in the left hemisphere of most right-handed individuals. Data for this view has been amassed from studies of split-brain (Sperry, Gazzaniga, \& Bogen, 1969; Dimond, 1972) and brain-lesioned patients (see reviews in Mountcastle, 1962; Vinken \& Bruyn, 1969; Gazzaniga, 1979) and of normals tested in dichotic listening (Kimura, 1961, 1967; Studdert-Kennedy \& Shankweiler, 1970; Berlin \& McNeil, 1976) and hemi-field visual stimulation paradigms (Bryden \& Rainey, 1963; see review by Levy, 1974). These convergent demonstrations of the functional specialization of the hemispheres have lead to the search for electrophysiological manifestations at the human scalp.

Comparisons between the left and right hemispheres in the amount of alpha EEG power produced during tasks which differentially engage the two hemispheres have yielded some positive results (Morgan, McDonald, \& MacDonald, 1971: Galin \& Ornstein, 1972; see review by Butler \& 
Glass, 1976); although the asymmetries reported have been small, they do seem to be consistent. Recently, however, the interpretation of the results of some of these original studies has been questioned. Possibly, many of these EEG asymmetries can be explained in terms of lateralized differences in task-related motor activity rather than the differential cognitive engagement of the hemispheres (Gevins, Zeitlin, Doyle, Schaffer, Yingling, Callaway, \& Jeager, 1979).

Success has been even more modest when indices of hemispheric utilization have been sought in the evoked or event-related potentials (ERPs) to specific sensory, motor, and/or cognitive events. This search has been fraught with conceptual and methodological difficulties. Given our inadequate understanding of the biophysical and functional properties of scalp-recorded brain potentials, few a priori predictions can be made about the nature of the hemispheric asymmetries being sought. Under the present circumstances, perhaps the best one can do is to catalogue the differences between the ERP waveforms of the two hemispheres as a function of the type of stimuli presented or the processing strategy invoked by the task instructions.

Much effort has gone into determining the extent to which different ERP components reflect the superior language processing capacities of the left hemisphere (see reviews in Desmedt, 1977b). A number of studies have reported an amplitude asymmetry in the ERP recorded over the language areas in the two hemispheres during tasks requiring some level of linguistic or semantic analysis for successful performance (Cohn, 1971; Morrell \& Salamy, 1971; Matsumiya, Tagliasco, Lombroso, \& Goodglass, 1972; Molfese, Freeman, \& Palermo, 1975; Preston et al., 1977; Thatcher, 1977; and Preston, 1979). Further, it has been reported that the left hemisphere generates varying ERPs depending upon the linguistic nature of the eliciting stimulus, whereas the right hemisphere appears insensitive to the verbal nature of the stimuli (Buchsbaum \& Fedio, 1969, 1970; Brown, Marsh, \& Smith, 1973, 1976; Wood, Goff, \& Day, 1971; Wood, 1975). Many of these reports have been criticized on methodological and statistical grounds, however (Friedman et al., 1975b; Galambos, Benson, Smith, Schulman-Galambos, \& Osier, 1975; Donchin, Kutas, \& McCarthy, 1977), and a number of other studies have noted a surprising absence of hemispheric asymmetry in the ERPs recorded during the performance of a language task (Shelburne, 1972, 1973; Galambos et al., 1975; Smith, Nielson, \& Thistle, 1975; Friedman et al., 1975a,b, 1977).

The majority of these latter studies, though methodologically sound and ingenious in design, have probably not adequately taxed the language system. As has been noted by several investigators, repeated presentations of simple, isolated syllables or even words are unlikely to engage normal language processes as consistently as would more natural contexts like conversation or reading. The present investigation allowed the as- 
sessment of hemispheric asymmetries of ERPs recorded from over Wernicke's area and its right hemisphere homologue in the context of natural sentence processing. For control purposes, a similar comparison of left and right hemisphere responses was made for the ERP waveforms elicited by repeated presentations of a single English word.

\section{The Effects of Unexpected Physical Deviations}

Numerous studies have affirmed that a late positive complex, generally referred to as the $\mathrm{P} 3$ or $\mathrm{P} 300$, is enhanced in amplitude when it is elicited by an infrequent or unexpected event (Sutton, Braren, Zubin, \& John, 1965; Tueting, Sutton, \& Zubin, 1971; see review by Donchin, Ritter, \& McCallum, 1978). While the relationship between P3 amplitude and subjective probability (expectancy) has not been delineated fully, headway has been made in modeling this relationship, particularly when two alternative stimuli are presented in a Bernoulli series (Squires, Wickens, Squires, \& Donchin, 1976; Duncan-Johnson \& Donchin, 1977; Squires, Petuchowski, Wickens, \& Donchin, 1977). In such instances, the P3 component to the less frequent stimulus is consistently larger than to the frequently presented stimulus. This finding is unequivocal when the infrequent stimulus is made "task relevant" by the experimenter; that is, if the subject must actively differentiate the infrequent stimulus from the others and acknowledge this selection with an overt or covert response. On occasion, stimuli having no assigned task relevance, presented infrequently, also have been demonstrated to generate P3 waves larger than to the frequent stimuli (Ritter, Vaughan, \& Costa, 1968; Roth, 1973; Courchesne, Hillyard, \& Galambos, 1975; Squires, Squires, \& Hillyard, 1975; Roth, Ford, Lewis \& Kopell, 1976; Snyder \& Hillyard, 1976; Courchesne, Courchesne \& Hillyard, 1977; Squires, Donchin, Herning, \& McCarthy, 1977). These effects, however, are characterized by variability in the P3 waveform and amplitude and are considered controversial. On the one hand, there is the question of whether the components measured in each of these investigations are one and the same process, which seems unlikely. On the other hand, there is the question of what the subjects were actually "doing in their mind" when they were instructed to ignore these infrequent stimuli.

Another goal of the present investigation was to evaluate the effect of any infrequent and "irrelevant" physical deviation (change in letter type and size) as subjects were silently reading sentences. The subjects were aware from the beginning of the task that some of the words might appear in a different typeface and, furthermore, that this change of type was inconsequential to their reading performance. In all instances, the physically deviant stimulus came at the seventh or last position in the sentence, such that $25 \%$ of the sentences ended with a word in heavy-faced type. This experiment on physical deviancy is one of a series we are conducting 
on ERPs to unexpected words in sentences which are physically, syntactically, semantically, or otherwise out of context.

\section{METHODS}

\section{Subjects}

Nine young adults (three male and six female, age range 18-25 years) were paid for participating in the experiment. All of the subjects were right-handed according to selfreport and as tested by the Edinburgh Inventory (Oldfield, 1971). Three of the subjects had participated in prior ERP experiments. Although the general nature of the experiment was explained, subjects were unaware of the specific hypotheses under investigation.

\section{Stimuli}

Slides containing single words were back-projected onto a translucent screen by a Kodak Carousel projector. Word onset and duration were controlled by a Ilex electronic shutter placed over the projector lens. Each word was flashed for $100 \mathrm{msec}$. The size of the image projected onto the screen by a single word was approximately $3.2 \mathrm{~cm}$ high and $12.1 \mathrm{~cm}$ wide for the "standard-sized," typewritten stimuli and $9.5 \mathrm{~cm}$ high and $18.4 \mathrm{~cm}$ wide for the large, heavy-faced stimuli that were constructed with Instantype (\#L-1026). Since the subjects sat approximately 2.06 meters from the screen, the words subtended a vertical angle of $0.89^{\circ}$ and $2.64^{\circ}$ for the standard and heavy-faced stimuli, respectively. The luminances of the backgrounds of these black-on-white slides ranged between 6.0 and 6.5 millilamberts.

Environmental sounds were masked by white noise presented through Koss stereophones.

\section{Recording System}

The electroencephalogram (EEG) was recorded from five electrodes, each referred to linked mastoids. The electrodes were placed according to the International 10-20 convention (Jasper, 1958) at frontal (Fz), central (Cz), and parietal (Pz) midline locations. Two lateral, temporo-parietal electrodes (W1 and W2) were placed lateral (by $30 \%$ of the interaural distance) and $12.5 \%$ posterior to the vertex. These placements have been reported to be situated over Wernicke's area and its right hemisphere homologue. Nonpolarizable Beckman $\mathrm{Ag}-\mathrm{AgCl}$ electrodes were secured to the subject's scalp with collodion. Electrode impedances did not exceed 2 Kohms. Eye movements and blinks were monitored via an electrode placed on the lower orbital ridge, referred to linked mastoids. In addition, a bipolar, right supraorbital to external canthal montage was used to record lateral eye movements (EOG).

The three midline and the lower eye derivations were amplified with Grass 7PI preamplifiers. The system bandpass was DC to $40 \mathrm{~Hz}$ (half-amplitude cutoff). The bipolar EOG and the lateral electrodes were amplified with Grass 7P5 preamplifiers (system bandpass down 3 $\mathrm{dB}$ at 0.15 and $150 \mathrm{c} / \mathrm{sec})$.

\section{Data Collection}

The experiment was controlled by prerecorded, coded trigger pulses from an audio tape recorder. The EEG, EOG, and trigger codes were recorded at $17 / 8$ i.p.s. on an 8-channel Vetter FM tape recorder. Analog to digital conversion was performed by a PDP 11/45 computer. A $1024 \mathrm{msec}$ epoch of EEG data, sampled at a rate of $4 \mathrm{msec}$ per point, was stored on magnetic tape for each word presented. Each epoch began $100 \mathrm{msec}$ preceding stimulus onset and lasted $924 \mathrm{msec}$ thereafter. The averaging and data analyses were also carried out on the PDP $11 / 45$. 


\section{Procedure}

Subjects were tested in one session that lasted $2 \frac{1}{2}$ to 3 hours. They were seated in a comfortable, reclining chair looking at the center of a projection screen and were informed that they would be presented with a series of simple, English sentences, one word at a time. Each sentence was a grammatically correct, meaningful unit in itself and did not bear any relation to preceding or following sentences. Subjects were told that the sentences were similar to one another in grammatical structure and that some might seem very familiar. Their instructions were to read each of the sentences silently in order to answer some questions about their contents at the end of the experiment.

The general timing sequence as well as two sample sentences can be seen in Fig. 1. The start of the sentence was signalled by a slide containing $x \times x \times x$. This was followed I sec later by the sequential presentation of the seven words at intervals of $1 / \mathrm{sec}$, the last of which was followed by a period indicating that the sentence was completed. After a 2-sec delay, the next sentence was presented and so on. The experimental sentences included 40 well known American cliches, 40 closed sentences for which the final position was limited to a single word to make it true, and 80 open-ended sentences, each of which could be completed by any of several words. In the analyses reported here, ERPs were averaged together across all sentence types.

At the beginning of the session, subjects were exposed to 10 practice sentences, with no ERPs being recorded. Two of these sentences ended with a word constructed with the physically deviant, heavy-faced type. The practice trials were followed by 16 experimental series of 10 sentences each. In a random $25 \%$ of these 160 sentences the seventh word appeared in the heavy-faced type. Each series of sentences was followed by a 2- to 3-min break. After the first eight series, subjects received an 8- to 10-min rest. No sentence was presented more than once during the experiment.

Following the completion of the sentence presentations each subject was asked to look at the screen where the word "station" was repeatedly flashed. There were two runs of 80 presentations each of this word. For four of the subjects, the word was typed in the standard size in the first run and was heavy-faced in the second series. For the remaining five subjects the order of these conditions was reversed.

\section{RESULTS AND DISCUSSION}

\section{General Characteristics of ERPs Elicited by Words}

Figure 2 shows the ERPs to the different classes of stimuli; from left to right are shown the ERPs to the warning stimulus (WS), to the first six words in the sentence (averaged together), to the standard-type seventh words (7-S) during the reading condition, and to the standard-size stimu-

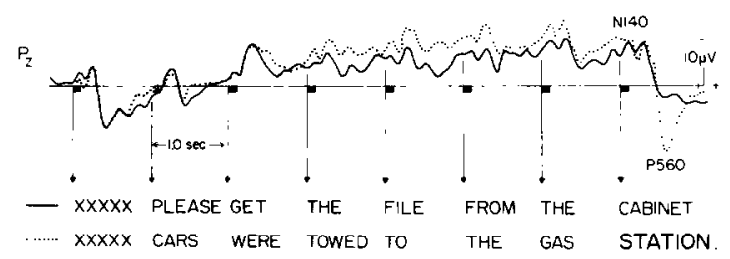

FIG. 1. Timing of word presentations illustrated for two sample sentences along with the concurrently recorded Contingent Negative Variation (CNV) recorded at $\mathrm{Pz}$ from one subject. The two superimposed waveforms represent the ERPs to sentences ending in standard-size type (solid line) and heavy-faced type (dashed line). Each tracing is an average of the responses to 40 different sentences. 

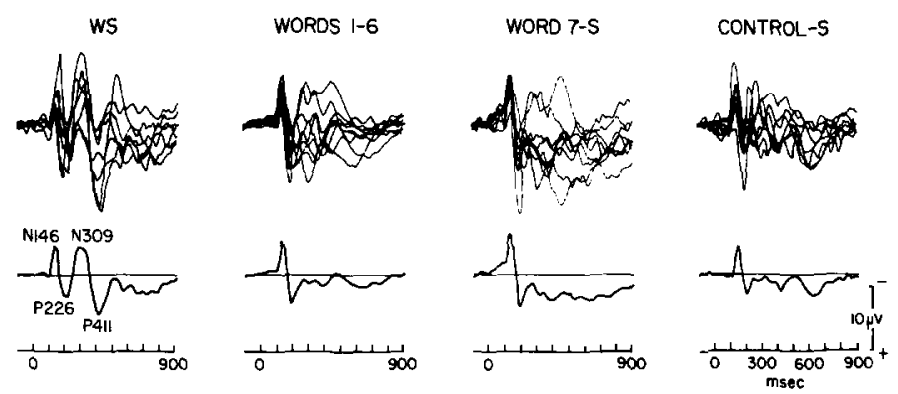

FIG. 2. ERPs to the warning stimulus (WS), to words 1 through 6 averaged together, to standard-type seventh words (word 7-S) and standard-type control words (control-S). Each of the superimposed tracings in the top row is the average of 25-40 responses from a different subject. The ERPs in the bottom row are the corresponding "grand average" waveforms over all subjects, recorded at Cz. ERPs from only seven of the nine subjects are presented for the WS. Two of the subjects did not have enough artifact free trials to constitute a reliable average, as they consistently blinked in response to WS.

lus during the control run. Each of the superimposed tracings in the top row is the averaged ERP at $\mathrm{Cz}$ from a different subject. The corresponding grand average waveforms over all subjects are presented below.

ERPs to the warning stimulus. As seen in Fig. 2, the warning stimulus elicited a very distinctive pattern of components which differs considerably from the responses elicited by any of the other stimuli. The typical response at $\mathrm{Cz}$ consisted of four identifiable components: an N146 $( \pm 3$ $\mathrm{msec})$, a P226 ( $\pm 8 \mathrm{msec})$, an N309 ( $\pm 11 \mathrm{msec})$, and a P411 ( $\pm 7 \mathrm{msec})$. The general waveshapes, amplitudes, latencies, and distributions of these components were quite consistent from subject to subject. The N146 component was approximately equal amplitude at frontal $(-5.5 \pm 0.7 \mu \mathrm{V})$ and central $(-5.4 \pm 1.2 \mu \mathrm{V})$ locations and tapered off over the parietal lead $(-2.7 \pm 1.1 \mu \mathrm{V})$. The P226 component likewise had a fronto-central distribution, being slightly larger over central $(5.0 \pm 1.0 \mu \mathrm{V})$ than frontal $(4.3 \pm 0.9 \mu \mathrm{V})$ regions and tapering off less than the N146 over the parietal site $(3.8 \pm 0.7 \mu \mathrm{V})$. The most striking aspect of the ERP to the warning stimulus was the large N309 component, which was larger over the frontal $(-6.2 \pm 1.6 \mu \mathrm{V})$ and central $(-5.9 \pm 1.7 \mu \mathrm{V})$ than parietal $(-4.7 \pm 1.3$ $\mu \mathrm{V})$ sites. The $\mathrm{N} 309$ component was followed by an equally large P41I wave which was of equal amplitude over the central $(6.8 \pm 2.0 \mu \mathrm{V})$ and parietal scalp $(6.4 \pm 1.8 \mu \mathrm{V})$ and was somewhat smaller at the frontal location $(5.0 \pm 1.3 \mu \mathrm{V})$. Neither the $\mathrm{N} 309$ nor the P411 components were evident in the waveforms to any of the other stimuli. The significance of these components is difficult to evaluate, but evidently they are related to the warning or timing function of the stimulus. Since the N309 has not been a prominent characteristic of ERPs previously reported to simple warning cues (e.g., Hillyard, Courchesne, Krausz, \& Picton, 1976), it may 
be associated only with the complex or linguistic variety of task used here.

ERPs to words 1-6. As can be seen in Fig. 2, the ERP waveforms elicited by the words during the reading task were highly variable across the subjects. Thus, the grand mean waveforms are not faithful representations of individual subject's ERPs, either for the averaged ERP to words 1 through 6 or to the last word in the sentence. The first two components elicited by words 1 through 6 (N144 and P204) were present and similar in all subjects; both components were distributed frontocentrally, as to the warning stimuli.

Beginning at about $250 \mathrm{msec}$ the components generated in response to words 1 to 6 in the sentence showed considerable intersubject variation. In particular, five of the nine subjects showed a consistently identifiable positive component within $300-400$ msec after stimulus onset; in those subjects this component averaged $346 \mathrm{msec}$ in latency and was rather small at frontal $(3.2 \pm 0.7 \mu \mathrm{V})$, central $(5.7 \pm 1.0 \mu \mathrm{V})$, and parietal locations $(4.7 \pm 0.8 \mu \mathrm{V})$. A similar component within the same latency range (mean of $338 \mathrm{msec}$ ) was also present for each of these same subjects in the ERPs elicited by the standard-size control words; its distribution was also similar, averaging $3.3 \pm 0.9 \mu \mathrm{V}$ at $\mathrm{Fz}, 6.2 \pm 1.4 \mu \mathrm{V}$ at $\mathrm{Cz}$, and 5.6 $\pm 1.2 \mu \mathrm{V}$ at $\mathrm{Pz}$. The presence of this late-positive component to the control words as well as to words in the sentences raises the possibility it was primarily a stimulus-evoked component unrelated to contextual sentence processing. On the other hand, it is possible that for some subjects the presentation of any word engaged the "P300" generator regardless of the nature of the task (Friedman et al., 1975b) In addition, three of these subjects also generated a later positive component, ranging from $3-10 \mu \mathrm{V}$ in amplitude, within 580-700-msec range.

Of the remaining four subjects, one had a large positive component at $460 \mathrm{msec}$ following a small negative deflection, two had large negative components rising at around $300 \mathrm{msec}$ which returned to baseline at 600 msec, and one had no identifiable components beyond the P204. The results for these four subjects are different from these reported by Friedman et al. (1975b), wherein a P300 was elicited to all words in a sentence regardless of whether or not they delivered information.

At present, we do not understand why it is that different subjects showed such divergent ERP waveforms during the reading condition. However, it should be noted that waveshapes of the ERPs to the first six words within the sentence were quite consistent within each subject. Possibly, this variation may be related to different processing strategies during reading.

ERPs to the standard last word. Like the ERPs to words 1 through 6, the ERPs to the standard-size 7th words were cha .cterized by frontocentral N143 and P202 components. The 7th worc esponses, however, 
did have a slightly larger N143 than did the average ERP to words $1-6$ at frontal $(5.3 \pm 0.8 \mu \mathrm{V})$, central $(6.4 \pm 0.7 \mu \mathrm{V}, t=2.67, p<.05)$, and parietal $(4.1 \pm 0.4 \mu \mathrm{V})$ sites.

The ERPs to the standard-size last words were also marked by appreciable intersubject variability, though, by and large, the 7th word averages were quite similar in waveshape to the ERPs averaged over the other words in the sentence. These ERPs did, however, have more late positivity in the 300-900-msec range than did the ERPs averaged across words 1 through 6 . The ERPs to the seventh words had more late positivity than the averages over the other words in the sentence for seven out of nine subjects at $\mathrm{Fz}$ (993 versus $217 \mu \mathrm{V}$-msec, $t=2.94, p<.02$ ), for eight out of nine subjects at $\mathrm{Cz}(2030$ versus $622 \mu \mathrm{V}$-msec, $t=3.19, p<.02)$ and for all the subjects at $\mathrm{Pz}(2062$ versus $282 \mu \mathrm{V}$-msec, $t=4.62, p<.01)$. Whereas this finding is generally consistent with the Friedman et al. (1975b) report that the last word in the sentence has the largest late positive component, there were a few subjects for whom other words in the sentence, particularly the first and the sixth, were associated with as much or slightly more late positivity.

Friedman et al. attributed the late positivity they observed after each word in the sentence to an enhanced P300 component. In fact, they suggested that "the enhancement of P300 to the last word of the sentence regardless of meaning and the point of task-related information delivery within the sentence suggests that this enhancement of P300 is a correlate of "syntactic closure'." However, as noted above, some of the subjects in the present experiment did not have appreciable $P 300$ waves to any of the words in the sentence. A few of those that did also produced similar late positive waves to the repeated presentation of the control stimulus word. Perhaps the difference betwecn our results and Friedman et al.'s has to do with the number of different sentences the subjects were exposed to ( 160 , none repeated versus three, repeated many times) or to the task requirements (simple reading versus making a decision). Thus, it would appear that the syntactic and semantic analyses involved in the more natural reading situation are not generally associated with robust $\mathrm{P} 300$ components. Further, it seems more reasonable to attribute most of the difference in the late positivity between the last word and the previous words in the sentence to the resolution of the $\mathrm{CNV}$, which developed and was maintained over the course of each sentence (Fig. 1), rather than to decision processes associated with sentence termination.

\section{Hemispheric Asymmetries}

The "grand mean" ERPs (averaged across all nine subjects) from the lateral sites during the reading and control conditions are depicted in Fig. 3. In each case, the ERPs recorded over Wernicke's area (solid line) and its right hemisphere homologue (dashed line) are superimposed. Left- 


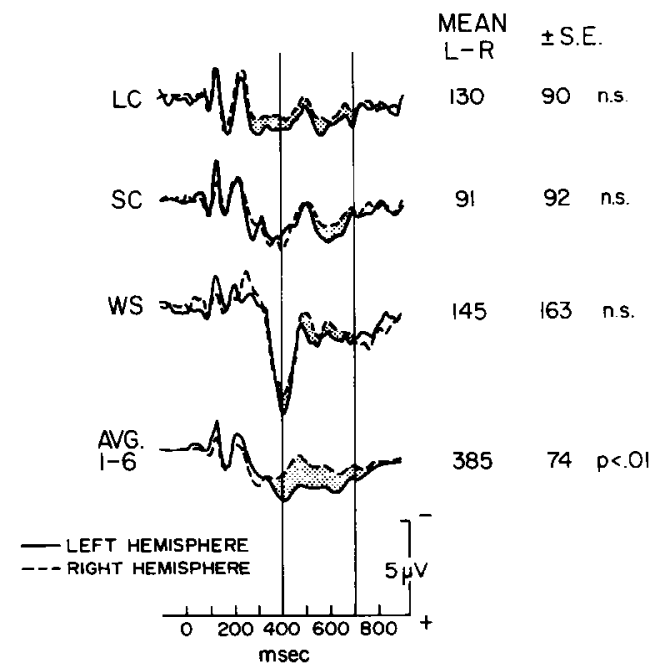

FIG. 3. A comparison of "grand average" ERPs (averaged across all subjects) recorded over Wernicke's area (W1, solid line) and its right hemisphere homologue (W2, dashed line) during the reading and control conditions. Right-left comparisons are presented for the ERPs elicited by repeated control presentations of the word "station" in heavy-faced type (LC) and in standard-size type (SC) and by the warning stimulus (WS), and by words 1 through 6 (averaged together) during sentence reading. To the right of the waveforms are the means and standard errors ( $\mathrm{SE}$ ) of the area (in $\mu \mathrm{V}-\mathrm{msec}$ ) of the left minus right difference in the region between the vertical lines, as well as the corresponding $p$-value for the Wilcoxon matched pairs signed-rank test.

right comparisons are presented for the ERPs to the warning stimuli (WS) and to the overall averaged ERP across the first six words in the sentence obtained during the reading task; also shown are evoked responses to repeated control presentations of the word "station" constructed in large characters (LC) and typed in small characters (SC). It is clear that the ERPs elicited by the control and warning stimuli are nearly symmetric, whereas the averaged ERP to the first six words in the sentence shows a prolonged positivity that is larger over the left than the right hemisphere. This asymmetry was evident in some subjects as early as $280 \mathrm{msec}$ following stimulus onset, though it was most consistent in the region from 400 to $700 \mathrm{msec}$.

As a measure of this hemispheric asymmetry we computed the area of the 300 -msec segment of the waveform between $400-$ and 700 -msec poststimulus, relative to a $90-\mathrm{msec}$ prestimulus baseline, for each hemisphere. The boundaries of these segments are shown as vertical lines in Fig. 3. The means and standard errors of the area differences between the right and left hemispheres in this latency zone are presented to the right of the corresponding waveforms. The extent to which the ERPs differed between the two hemispheres, as indexed by this area measure, was evaluated using Wilcoxon and paired $t$-tests. The resultant $p$-values are 
shown in the right-most column of Fig. 3. These analyses corroborate what was evident after visual inspection of the waveforms; that is, the ERP over the left hemisphere was characterized by a prolonged positivity which was significantly greater than that over the the right hemisphere for the first six words in the sentence, but not for either of the control conditions or for the warning stimulus.

The results of a similar analysis performed on each of the words in the sentence separately are presented in Fig. 4 along with the corresponding waveforms. These findings indicate that the left hemisphere was significantly more positive than the right hemisphere for ERPs elicited by all but the first word in the sentence. Only one subject did not exhibit a left-greater-than-right positivity in the ERP averaged over words 1 through 6 in the sentence.

Although the grand average ERPs elicited by the words and by control stimuli also seem to show a left-greater-than-right asymmetry in the N140 component at the lateral sites, a statistically significant difference $(p<$ .01 ) was found only for the ERPs to the seventh word (mean difference of $1.3 \pm 0.8 \mu \mathrm{V}$ ), using both the Wilcoxon and paired $t$ tests. This finding is tantalizing but must be replicated before it can be taken seriously.

In light of the slight trend for the N140 to be more negative over the left

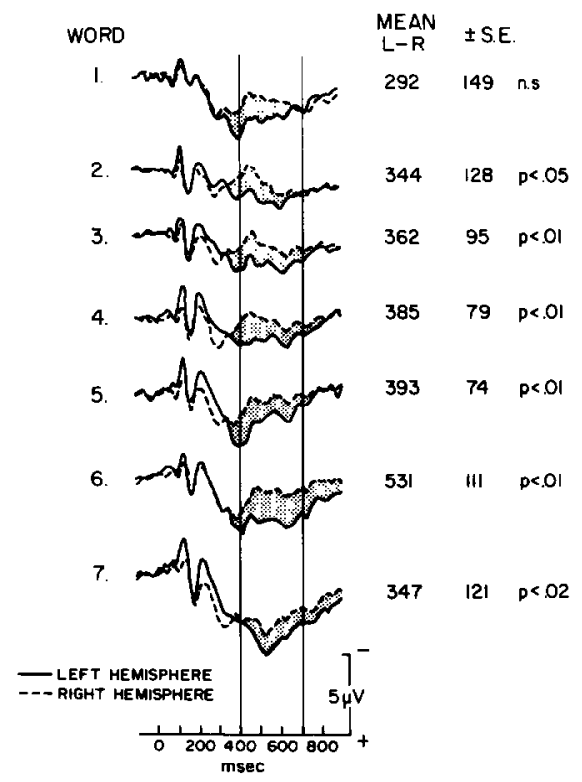

FIG. 4. In the left column are the scalp-recorded potentials to each of the seven words in the sentence. In each comparison, the "grand average" ERPs from homologous locations over the left and right parietal areas are superimposed. In the right column the corresponding means and SE's of the area of the left-minus-right difference (in $\mu \mathrm{V}$-msec) between 300 and $700 \mathrm{msec}$ are presented. $p$-values are for Wilcoxon matched pairs signed-ranks tests. 
than the right hemisphere, an analysis of the lateral distribution of the P180 component was also carried out to determine whether the hemispheric asymmetry was localized to the region of prolonged positivity. The mean amplitude difference between the left and right hemispheres in the $\mathrm{P} 180$ component was found to be $-0.2 \pm 0.6 \mu \mathrm{V}$; this component was larger on the left than the right for four of the nine subjects and larger on the right than the left for the remaining five subjects. Thus, the left hemisphere ERP was not larger than its right hemisphere counterpart throughout the entire epoch, but rather the asymmetry was restricted to the positivity in the post-300 msec range.

These data are in line with several recent reports of a prolonged positive electrogenesis in the later regions (post-300 msec) of the ERP, larger over the left than the right hemisphere for language-related tasks (Preston, 1979) and larger over the right than the left hemisphere in tasks requiring spatial analysis (Desmedt, 1977a; see Neville, 1980). However, as tempting as it may be to suggest that the sustained asymmetry present in the ERPs to words in a sentence context is a reflection of the specific engagement of language systems in the left hemisphere, the data can be interpreted in other ways. For example, it may be the extraction of meaning rather than the linguistic analysis per se which is indexed by this asymmetric ERP component. Thus, ERPs were symmetric to the repeated control words and, in previous experiments, to sentences which were so predictable as to convey little semantic information (Friedman et al., 1975b).

\section{The Effects of Unexpected Physical Deviations}

The ERPs elicited at the Pz electrode by the infrequent, larger words are displayed in Fig. 5 (solid lines) for each subject. Superimposed upon each of these waveforms is the averaged ERP over the seventh words from the remaining $75 \%$ of the sentences (dashed lines) which ended with a word in small typeface like that of the preceding words in the sentence. The grand average waveforms across all nine subjects are presented at the bottom of the right column. It is apparent that despite the intersubject variability in waveshape, the infrequently presented, large typeface was associated with appreciably more late positivity than the more frequently presented smaller words. (The one exception was Subject 8 who showed a late negativity to this physically deviant stimulus.)

This late positivity was first quantified overall as the area under the curve from 400 - to 900 -msec post-stimulus, relative to a 90 -msec prestimulus baseline. A comparison of these areas for the two types of seventh words substantiates the visual impression that the ERPs elicited by the infrequent, physically deviant stimuli had more late positivity than the ERPs to the frequent words at the frontal (3268 versus $701 \mu \mathrm{V}$-msec), 

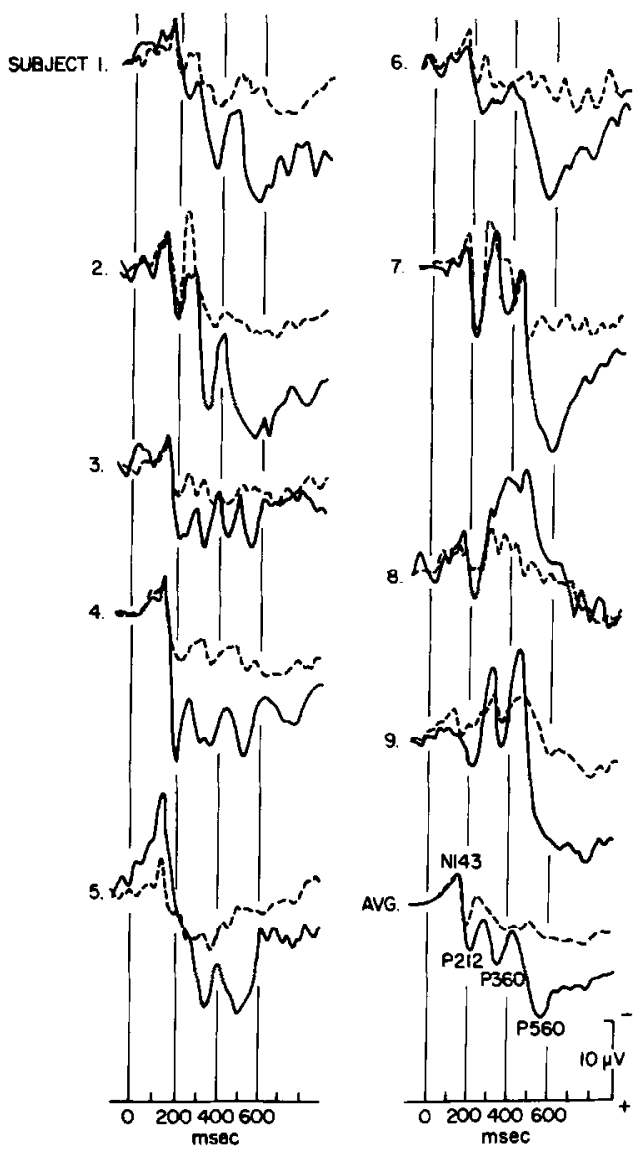

FIG. 5. Comparison of ERPs to the last words made of standard-size (dashed line) and heavy-faced (solid line) type for each of the nine subjects at Pz. The waveforms in the bottom right corner are the "grand average" responses across all the subjects.

central (5361 versus $1694 \mu \mathrm{V}$-msec) and parietal (5103 versus $1842 \mu \mathrm{V}$ msec) sites $(p<.01$ for all comparisons by Wilcoxon test).

A finer-grained analysis of the ERPs to the seventh word reveals that the effect of the infrequent change in typeface was manifest throughout the waveform, beginning as early as $190-\mathrm{msec}$ post-stimulus. There were three major regions of the ERP, at 180-220, 300-400, and 400-650 msec, in which the ERPs to infrequent and frequent seventh words differed most clearly. The means and standard errors of the base-to-peak amplitudes of these three positive components (P212, P360, and P560) at the frontal, central, and parietal sites are shown in Table 1. The amplitudes of these components for the waveforms at the $\mathrm{Cz}$ electrode to the frequent seventh words and the control runs are also included in the table. Measurements 


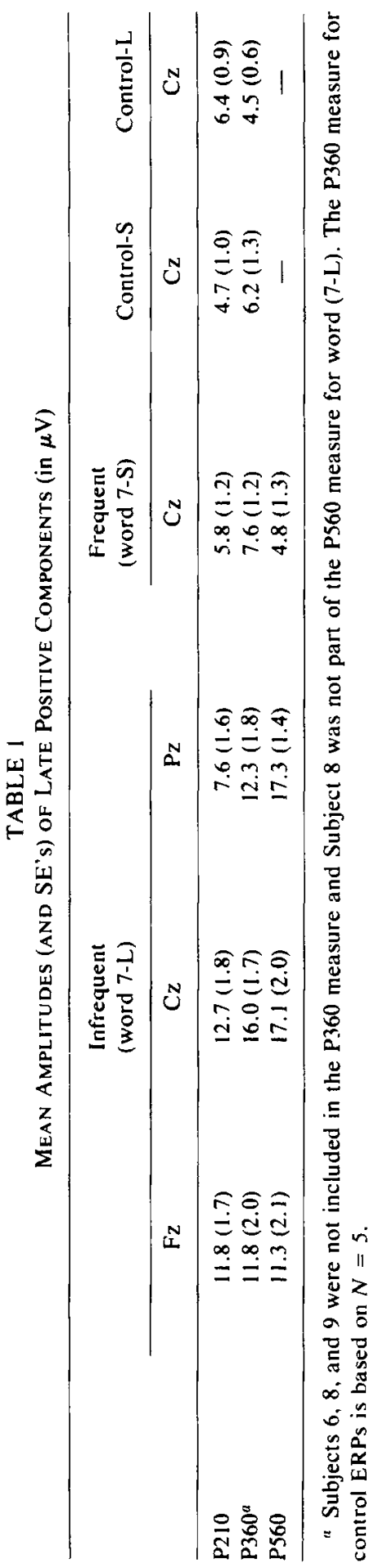


were made by computer on each individual's ERP; however, the means and SE's presented in Table 1 are based only upon data from those subjects whose waveforms included the component under evaluation. In most subjects, the ERP to the infrequent stimulus was characterized by a more distinctive and larger positive component in each of these three regions.

The effect of the infrequent physical deviation on components within the 180-220-msec range can also be assessed in the difference waveform obtained by subtracting the ERP elicited by the frequent stimuli from that elicited by the infrequent stimuli. This analysis indicates that the largest difference between the ERPs to large and small seventh words in this region was at $220 \pm 4 \mathrm{msec}$ and was fairly evenly distributed over frontal (8.1 $\pm 1.3 \mu \mathrm{V})$, central $(9.3 \pm 1.4 \mu \mathrm{V})$, and parietal $(7.2 \pm 1.2 \mu \mathrm{V})$ sites.

A similar, though smaller, effect in this latency range was obtained when the amplitudes of the P180-220 component for the small and large control ERPs were compared (see Table 1). The fact that the P220 component was larger in the ERPs elicited by the boldfaced type than by the small type in seven of nine subjects, even when the stimuli were repeatedly flashed, suggests that part of the relative enhancement in the amplitude of the P220 elicited by the infrequent larger seventh word may be the result of the physical differences between the two categories of seventh word stimuli. Whereas these amplitude differences in the 180220-msec range relative to the same difference for the control ERPs may be somewhat inflated by the CNV resolution, they are clearly too large to be attributed entirely to the change in physical parameters and presentation rate. A similar increase in the amplitude of a P180-220 component elicited by infrequent stimuli is evident in other reports comparing the ERPs to frequent and infrequent stimuli (see for example, Fig. 1, Sutton et al., 1965; Courchesne et al., 1977; Courchesne, Courchesne, \& Hillyard, 1978, Fig. 1a; Duncan-Johnson \& Donchin, 1977).

In six of the subjects, the infrequent physical deviation also had an effect within the 300-400-msec range. Analysis of the seventh word difference waveforms indicates that at $335-355 \mathrm{msec}$, the ERPs elicited by the infrequent stimuli were larger on the average by $7.5 \pm 1.6 \mu \mathrm{V}$ at frontal, $10.9 \pm 1.3 \mu \mathrm{V}$ at central, and $10.3 \pm 0.9 \mu \mathrm{V}$ at parietal locations than the ERPs elicited by the frequent seventh word stimuli.

The largest and most consistent component elicited by the physically distinct seventh word was a broad, centro-parietal late positive wave with a mean latency of $560 \pm 12 \mathrm{msec}$. This P560 was larger for the infrequent than the frequent stimuli at the frontal (by $9.0 \pm 1.8 \mu \mathrm{V}$ ), central (by 13.1 $\pm 1.5 \mu \mathrm{V}$ ), and parietal (by $13.4 \pm .9 \mu \mathrm{V}$ ) locations. This component was not present in the control ERPs elicited by the repeated presentation of a word in heavy-faced type. Thus, this effect is not merely a result of the physical characteristics of the word. 
It is apparent that the occasional occurrence of a word presented in a discrepant letter type and size in this silent reading situation results in a complex series of changes in the later portions of the ERP. The distributions of these various ERP components appear to be different enough to suggest that there are at least two, possibly three, overlapping phenomena within the $180-$ to $900-\mathrm{msec}$ interval following the presentation of the infrequent stimulus. Whereas the effect of the physical deviation on the ERP is similar at all electrode sites within the P180-220-msec range, the effect becomes progressively more parietal through the remaining 700 msec in the epoch. The complexity of the waveforms elicited by the physically deviant seventh words and the similar sensitivity of each of the three positive components to this discrepancy does not point to a straightforward correspondence with the "traditional" P3 component. Nonetheless, the distribution of the P560 component is most consistent with that reported for the $\mathrm{P} 3$ waves which follow infrequent events.

It is also interesting to note that the physically deviant stimuli elicited a complex of large, late positive components, even though the change in the typeface was not relevant to the subject's task of sentence comprehension. This is consonant with the reports of Courchesne et al., (1978) and others (Squires, Donchin, Squires, \& Grossberg, 1977) that an occasional physical deviation from a constant background results in the generation of a large P3 component in adults. It was the case, however, that the sentence reading was a fairly simple task, allowing subjects "processing time" for the physical deviation. In fact, there is some evidence (Heffley, Wickens, \& Donchin, 1978) that the more difficult the primary task the smaller the amplitude of the P3 to irrelevant physical deviations (presumably because the stimulus is "truly" ignored). Such results suggest that wholly irrelevant stimuli may at times engage the P3 generating system, when they are difficult to ignore completely.

Equally interesting is the observation that each word in the sentence or each grammatical category, given that they are quite infrequent, does not yield a large P3 component. This finding has been attributed to the reader's grouping of different stimuli into fewer categories, the more infrequent of which is associated with a large P3. The major weakness of this interpretation is the difficulty in explicating the rules by which subjects "consciously or unconsciously" categorize events. It is also possible, however, that the types of expectancies that develop and are confirmed or disconfirmed during language processing are different from those associated with P3 generation.

\section{REFERENCES}

Berlin, C. I., \& McNeil, M. R. 1976. Dichotic listening. In N. J. Lass (Ed.), Contemporary issues in experimental phonetics. New York: Academic Press.

Brown, W. S., Marsh, J. T., \& Smith, J. C. 1973. Contextual meaning effects on speech evoked potentials. Behavioral Biology, 9, 755-761. 
Brown, W. S., Marsh, J. T., \& Smith, J. C. 1976. Evoked potential waveform differences produced by the perception of different meanings of an ambiguous phrase. Electroencephalography and Clinical Neurophysiology, 41, 13-123.

Bryden, M. P., \& Rainey, C. A. 1963. Left-right differences in tachistoscopic recognition. Journal of Experimental Psychology, 66(6), 568-571.

Buchsbaum, M., \& Fedio, P. 1969. Visual information and evoked responses from the left and right hemispheres. Electroencephalography and Clinical Neurophysiology, 26, 266-272.

Buchsbaum, M., \& Fedio, P. 1970. Hemispheric differences in evoked potentials to verbal and non-verbal stimuli in the left and right visual fields. Physiology and Behavior, 5, 207-210.

Butler, S. R., \& Glass, A. 1976. EEG correlates of cerebral dominance. In A. H. Riesen \& R. F. Thompson (Eds.), Advances in psychobiology, Vol. 3. New York: Wiley. Pp. 219-272.

Cohn, R. 1971. Differential cerebral processing of noise and verbal stimuli. Science, 72, 599-601.

Conners, C. K. 1970. Cortical visual evoked response in children with learning disorders. Psychophysiology, 7, 418-428.

Courchesne, E., Courchesne, R. Y., \& Hillyard, S. A. 1978. The effect of stimulus deviation on $\mathrm{P} 3$ waves to easily recognized stimuli. Neuropsychologia, 16, 189-199.

Courchesne, E., Hillyard, S. A., \& Courchesne, R. Y. 1977. P3 waves to the discrimination of targets in homogeneous and heterogeneous stimulus sequences. Psychophysiology, 14(6), 590-597.

Courchesne, E., Hillyard, S. A., \& Galambos, R. 1975. Stimulus novelty, task relevance and the visual evoked potential in man. Electroencephalography and Clinical Neurophysiology, 39, 131-143.

Desmedt, J. E. 1977a. Active touch exploration of extra-personal space elicits specific electrogenesis in the right cerebral hemisphere of intact right-handed man. Proceedings of National Academy of Sciences USA, 74(9), 4037-4040.

Desmedt, J. E. (Ed.) 1977b. Language and hemispheric specialization in man: Cerebral ERPs. Progress in Clinical Neurophysiology, Vol. 3. Basel: Karger Press.

Dimond, S. 1972. The double brain. London: Whitefriars Press.

Donchin, E., Kutas, M., \& McCarthy, G. 1977. Electrocortical indices of hemispheric utilization. In S. Harnad, R. Doty, L. Goldstein, J. Jaynes, \& G. Krauthamer (Eds.), Lateralization in the nervous system. New York: Academic Press. Pp. 339-384.

Donchin, E., Ritter, W., \& McCallum, W. C. 1978. Cognitive psychophysiology: The endugenuus components of the ERP. In E. Callaway, P. Tueting, \& S. H. Koslow (Eds.), Event-related brain potentials in man. New York: Academic Press. Pp. 349411.

Duncan-Johnson, C. C.. \& Donchin. E. 1977. On quantifying surprise: The variation in event-related potentials with subjective probability. Psychophysiology, 14, 456-467.

Friedman, D., Simson, R. Ritter. W., \& Rapin, I. 1975a. Cortical evoked potentials elicited by real speech words and human sounds. Electroencephalography and Clinical Neurophysiology, 38, 13-19.

Friedman, D., Simson, R., Ritter, W., \& Rapin, I. 1975b. The late positive component (P300) and information processing in sentences. Electroencephalography and Clinical Neurophysiology, 38, 255-262.

Friedman, D., Simson, R.. Ritter, W., \& Rapin, I. 1977. CNV and P300 experimental paradigms for the study of language. In J. E. Desmedt (Ed.), Language and hemispheric specialication in man: Cerebral ERPs. Progress in Clinical Neurophysiology, Vol. 3. Basel: Karger Press. Pp. 205-211.

Galambos, R., Benson, P., Smith, T. S., Schulman-Galambos, C., \& Osier, H. 1975. On 
hemispheric differences in evoked potentials to speech stimuli. Electroencephalography and Clinical Neurophysiology, 39, 279-283.

Galin, D., \& Ornstein, R. 1972. Lateral specialization of cognitive mode: An EEG study. Psychophysiology, 9, 412-418.

Gazzaniga, M. S. (Ed.) 1979. Handbook of behavioral neurobiology, Vol. 2, Neuropsychology. New York: Plenum Press.

Gevins, A. S., Zeitlin, G. M., Doyle, J. C., Schaffer, R. E., Yingling, C. D., Callaway, E., \& Yeager, C. L. 1979. Electroencephalogram correlates of higher cortical functions. Science, 203, 665-667.

Goto, H., Adachi, T., Utsunomiya, T., \& Chen, I.-C. 1979. Late positive component (LPC) and CNV during processing of linguistic information. In D. Lehmann \& E. Callaway (Eds.) Human evoked potentials applications and problems. New York: Plenum Press. Pp. 121-134.

Heffley, E., Wickens, C., \& Donchin, E. 1978. Intramodality selective attention and P300-Reexamination in a visual monitoring task. Psychophysiology, 15, 269-270.

Hillyard, S. A., Courchesne, E., Krausz, H. I., \& Picton, T. W. 1976. Scalp topography of the "P3" wave in different auditory decision tasks. In W. C. McCallum \& J. R. Knott (Eds.) The responsive brain. Bristol: John Wright \& Sons. Pp. 81-87.

Hillyard, S. A., \& Woods, D. L. 1979. Electrophysiological analysis of human brain function. In M. S. Gazzaniga (Ed.), Handbook of behavioral neurobiology, Vol. 2. New York: Plenum Press. Pp. 345-378.

Jasper, H. H. 1958. Report of the committee on methods of clinical examination in electromyography. Electroencephalography and Clinical Neurophysiology, 10, 370-375.

Kimura, D. 1961. Cerebral dominance and the perception of verbal stimuli. Canadian Journal of Psychology, 15, 166-171.

Kimura, D. 1967. Functional asymmetry of the brain in dichotic listening. Cortex, 3, 163-178.

Levy, J. 1974. Psychobiological implications of bilateral asymmetry. In S.J. Dimond \& J. G. Beaumont (Eds.), Hemisphere function in the human brain. New York: Halstead Press. Pp. 121-183.

Matsumiya, Y., Tagliasco, V., Lombroso, C. T., \& Goodglass, H. 1972. Auditory evoked response: Meaningfulness of stimuli and interhemispheric asymmetry. Science, 175, $790-792$.

Molfese, D. L., Freeman, R. B., Jr., \& Palermo, D. S. 1975. The autogeny of brain lateralization of speech and nonspeech stimuli. Brain and Language, 2, 356-368.

Morgan, A. H., McDonald, P. J., \& MacDonald, H. 1971. Differences in bilateral alpha activity as a function of experimental task with a note on lateral eye movements and hypnotizability. Neuropsychologia, 9, 459-469.

Morrell, L., \& Salamy, J. 1971. Hemispheric asymmetry of electrocortical responses to speech stimuli. Science, 174, 164-166.

Mountcastle, V. B. (Ed.) 1962. Interhemispheric relations and cerebral dominance. Baltimore: Johns Hopkins Press.

Neville, H. J. 1980. Event-related potentials in neuropsychological studies of language. Brain and Language, 11, 300-318.

Oldfield, R. C. 1971. The assessment and analysis of handedness: The Edinburgh inventory, Neuropsychologia, 9, 97-113.

Preston, M. S. 1979. The use of evoked response procedures in studies of reading disability. In H. Begleiter (Ed.), Evoked brain potentials and behavior. New York: Plenum Press. Pp. 247-268.

Preston, M. S., Guthrie, J. T., \& Childs, B. 1974. Visual evoked responses (VERs) in normal and disabled readers. Psychophysiology, 11, 452-457.

Preston, M. S., Guthrie, J. T., Kirsch, I., Gertman, D., \& Childs, B. 1977. VERs in normal and disabled adult readers. Psychophysiology, 14, 8-14. 
Ritter, W., Vaughan, H., Jr., \& Costa, L. 1968. Orienting and habituation to auditory stimuli: A study of short term changes in averaged evoked responses. Electroencephalography and Clinical Neurophysiology, 25, 550-560.

Ross, J. J., Childers, D. G., \& Perry, N. W. 1973. The natural history and electrophysiological characteristics of familial language dysfunction. In P. Satz, \& J. T. Ross (Eds.), The disabled learner: Early detection and intervention. Rotterdam: University of Rotterdam Press. Pp. 149-174.

Roth, W. T. 1973. Auditory evoked responses to unpredictable stimuli. Psychophysiology, 10, $125-138$.

Roth, W. T., Ford, J. M., Lewis, S. J., \& Kopell, B. S. 1976. Effects of stimulus probability and task-relevance on event-related potentials. Psychophysiology, 13, 311-317.

Shelburne, S. A., Jr. 1972. Visual evoked responses to word and nonsense syllable stimuli. Electroencephalography and Clinical Neurophysiology, 32, 17-25.

Shelburne, S. A., Jr. 1973. Visual evoked responses to language stimuli in normal children. Electroencephalography and Clinical Neurophysiology, 34, 135-143.

Shipley, T., \& Jones, R. W. 1969. Initial observations on sensory interaction and the theory of dyslexia. Journal of Communication Disorders, 2, 295-311.

Smith, T. S., Nielson, B., \& Thistle, A. B. 1975. Question of asymmetries in auditory evoked potentials to speech stimuli. Journal of Acoustical Society of America, 58(1), 557.

Snyder, E., \& Hillyard, S. A. 1976. Long-latency evoked potentials to irrelevant deviant stimuli. Behavioral Biology, 16, 319-331.

Sobotka, K. R., \& May, J. G. 1977. Visual evoked potentials and reaction time in normal and dyslexic children. Psychophysiology, 14, 18-24.

Sperry, R. W., Gazzaniga, M. S., \& Bogen, J. E. 1969. Interhemispheric relationships: The neocortical commissures; Syndromes of hemispheric disconnection. In P. J. Vinken \& G. W. Bruyn (Eds.) Handbook of clinical neurology, Vol. 4. Amsterdam: NorthHolland. Pp. 273-290.

Squires, K. C., Donchin, E., Herning, I., \& McCarthy, G. 1977. On the influence of task relevance and stimulus probability on event-related potential components. Electroencephalography and Clinical Neurophysiology, 42, 1-14.

Squires, K. C., Petuchowski, S., Wickens, C., \& Donchin, E. 1977. The effects of stimulus sequence on event-related potentials: A comparison of visual and auditory sequences. Perception and Psychophysics, 22(1), 31-40.

Squires, K. C., Wickens, C., Squires, N. K., \& Donchin, E. 1976. The effect of stimulus sequence on the waveform of the cortical event-related potential. Science, 193, 11421146.

Squires, N. K., Donchin, E., Squires, K. C., \& Grossberg, S. 1977. Bisensory stimulations inferring decision-making processes from the $\mathrm{P} 300$ component. Journal of Experimental Psychology. Human Perception \& Performance, 3, 299-315.

Squires, N. K., Squires, K. C., \& Hillyard, S. A. 1975. Two varieties of long-latency positive waves evoked by unpredictable auditory stimuli. Electroencephalography and Clinical Neurophysiology, 38, 387-401.

Studdert-Kennedy, M., \& Shankweiler, D. 1970. Hemispheric specialization for speech perception. Journal of Acoustical Society of America, 48, 579-594.

Sutton, S., Braren, M., Zubin, J., \& John, E. R. 1965. Evoked-potential correlates of stimulus uncertainty. Science, 150, 1187-1188.

Symann-Louett, N., Gascon, G. G., Matsumiya, Y., \& Lombroso, C. T. 1977. Waveform differences in visual evoked responses between normal and reading disabled children. Neurology, 27, 156-159.

Thatcher, R. W. 1977. Evoked potential correlates of hemispheric lateralization during semantic information processing. In S. Harnad, R. Doty, L. Goldstein, J. Jaynes, \& G. Krauthamer (Eds.), Lateralization in the nervous system. New York: Academic Press. Pp. 429-448. 
Tueting, P., Sutton, S., \& Zubin, J. 1971. Quantitative evoked potential correlates of the probability of events. Psychophysiology, 7, 385-394.

Vinken, P. J., \& Bruyn, G. W. (Eds.) 1969. Handbook of clinical neurology, Vol. 4, Disorders of speech, perception and symbolic behavior. Amsterdam: North-Holland.

Weber, B. A. , \& Omenn, G. S. 1977. Auditory and visual evoked responses in children with familial learning disabilities. Journal of Learning Disabilities, 10, 32-158.

Wood, C. C. 1975. Auditory and phonetic levels of processing in speech perception: Neurophysiological and information-processing analyses. Journal of Experimental Psychology, 104, 3-20.

Wood, C. C., Goff, W. R., \& Day, R. S. 1971. Auditory evoked potentials during speech perception. Science, 173, 1248-1251. 